\title{
Corrigendum
}

\section{Corrigendum to “A Fractional Trust Region Method for Linear Equality Constrained Optimization"}

\author{
Honglan Zhu, ${ }^{1,2}$ Qin $\mathrm{Ni}^{1}{ }^{1}$ Liwei Zhang, ${ }^{3}$ and Weiwei Yang' \\ ${ }^{1}$ College of Science, Nanjing University of Aeronautics and Astronautics, Nanjing 210016, China \\ ${ }^{2}$ Business School, Huaiyin Institute of Technology, Huai'an 223003, China \\ ${ }^{3}$ Jiangsu Cable, Nanjing 210000, China \\ Correspondence should be addressed to Qin Ni; niqfs@nuaa.edu.cn \\ Received 19 December 2016; Accepted 4 January 2017; Published 5 March 2017 \\ Copyright (C) 2017 Honglan Zhu et al. This is an open access article distributed under the Creative Commons Attribution License, \\ which permits unrestricted use, distribution, and reproduction in any medium, provided the original work is properly cited.
}

In the article titled "A Fractional Trust Region Method for Linear Equality Constrained Optimization” [1], Dr. Honglan Zhu was incorrectly listed as the corresponding author. The corresponding author is Dr. Qin Ni.

\section{References}

[1] H. Zhu, Q. Ni, L. Zhang, and W. Yang, "A fractional trust region method for linear equality constrained optimization," Discrete Dynamics in Nature and Society. An International Multidisciplinary Research and Review Journal, vol. 2016, Article ID 8676709, 10 pages, 2016. 


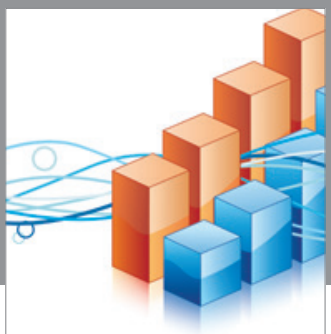

Advances in

Operations Research

vatem alat4

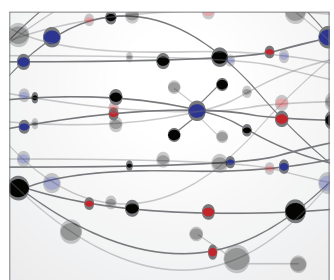

\section{The Scientific} World Journal

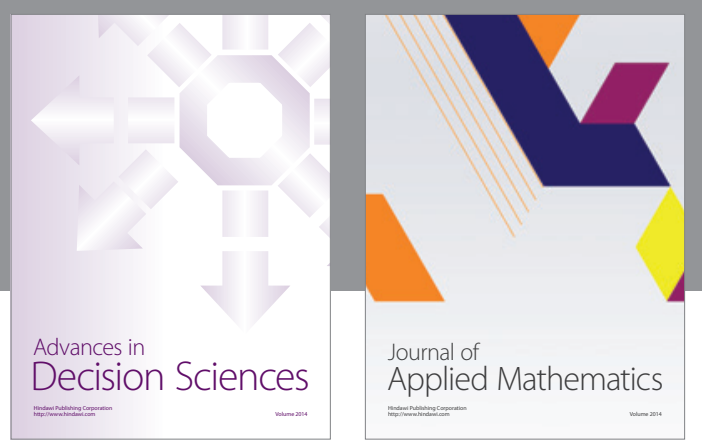

Algebra

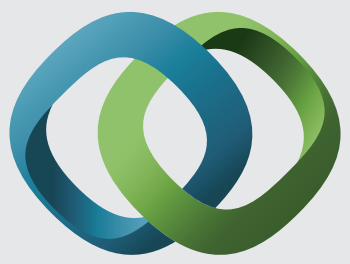

\section{Hindawi}

Submit your manuscripts at

https://www.hindawi.com
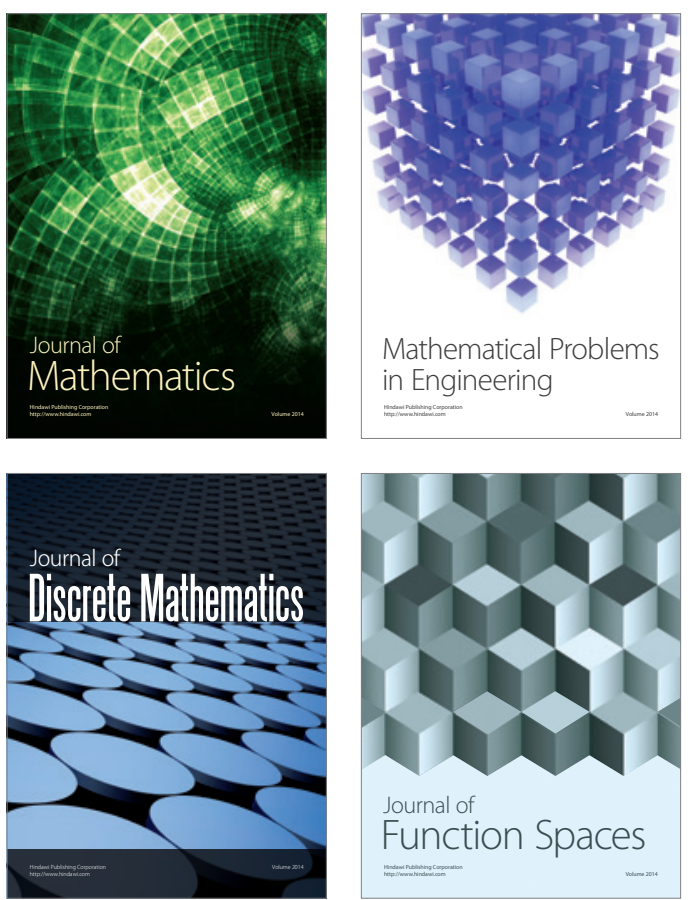

Mathematical Problems in Engineering
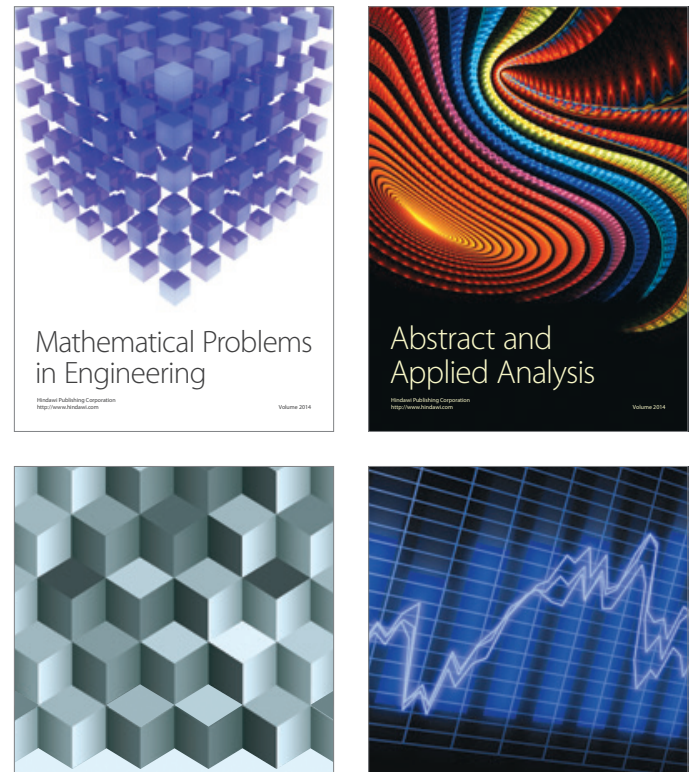

Journal of

Function Spaces

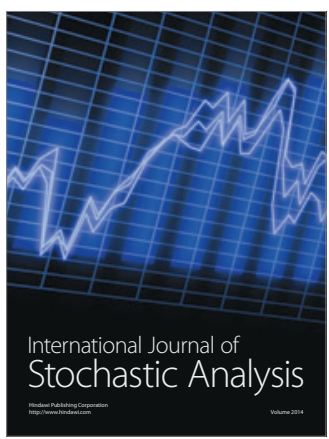

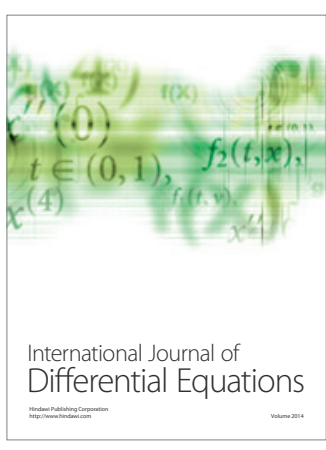
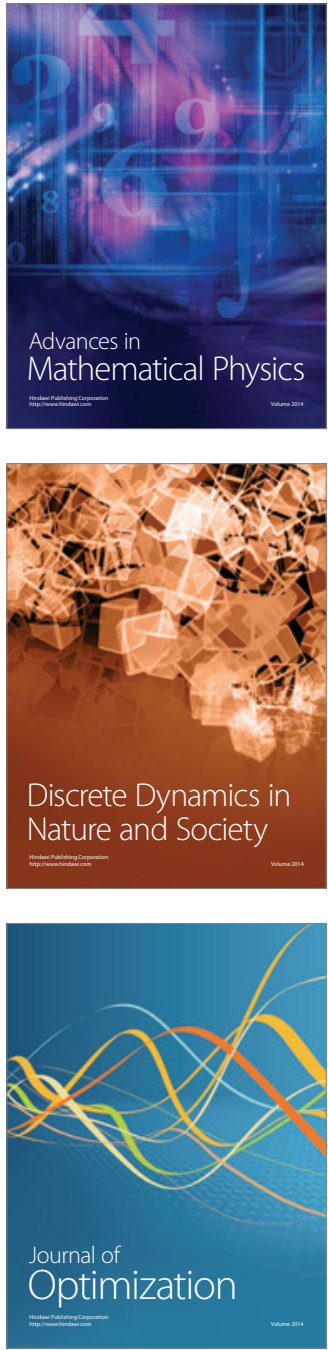